\title{
RE: Field triage in trauma - do the data really justify the conclusions?
}

\author{
Marius Rehn*1,2, Torsten Eken ${ }^{3}$, Andreas Jorstad Krüger ${ }^{1,4}$, \\ Petter Andreas Steen ${ }^{2,5}$, Nils Oddvar Skaga ${ }^{1,6}$ and Hans Morten Lossius ${ }^{1}$
}

\begin{abstract}
Address: ${ }^{1}$ Department of Research and Development, Norwegian Air Ambulance Foundation, Drobak, Norway, ${ }^{2}$ Faculty of Medicine, Faculty Division Ulleval University Hospital, University of Oslo, Norway, ${ }^{3}$ Department of Anaesthesiology, Aker University Hospital, Oslo, Norway, ${ }^{4}$ Department of Anaesthesiology and Emergency Medicine, St Olav University Hospital, Trondheim, Norway, ${ }^{5}$ Prehospital division, Ulleval University Hospital, Oslo, Norway and 'Department of Anaesthesiology, Division of Emergency Medicine, Ulleval University Hospital, Oslo, Norway
\end{abstract}

Email: Marius Rehn* - marius.rehn@snla.no; Torsten Eken - torsten.eken@medisin.uio.no; Andreas Jorstad Krüger - andreas.kruger@snla.no; Petter Andreas Steen - p.a.steen@medisin.uio.no; Nils Oddvar Skaga - n.o.skaga@medisin.uio.no;

Hans Morten Lossius - hans.morten.lossius@snla.no

* Corresponding author

Published: 29 May 2009

Scandinavian Journal of Trauma, Resuscitation and Emergency Medicine 2009, 17:25

This article is available from: http://www.sjtrem.com/content/I7/I/25

(C) 2009 Rehn et al; licensee BioMed Central Ltd.

This is an Open Access article distributed under the terms of the Creative Commons Attribution License (http://creativecommons.org/licenses/by/2.0), which permits unrestricted use, distribution, and reproduction in any medium, provided the original work is properly cited.
Received: 12 May 2009

Accepted: 29 May 2009

\section{Letter \\ Dear Sir,}

Thank you for your interest in our article; "Precision of field triage in patients brought to a trauma centre after introducing trauma team activation guidelines" [1], which gives us the opportunity for expounding some conclusions that could be open for misinterpretation.

We agree with Dr. Sandberg that paramedics and anaesthetists conduct missions with very skewed profiles. We suspect that this mission-selection bias applies to all anaesthetists-manned services, regardless of transport method. The differences in task profile may be beyond the scope of statistical adjustment contributing to a contracomparison line of argumentation. This is a problem in most epidemiologic studies. What is found is an association between factors; a good starting point for prospective intervention studies. In this case possibly testing changes in one or more of the links in the triage chain. Hopefully, readers agree with us in our statement "skewed mission profiles make comparison of differences in triage precision difficult".

Dr. Sandberg correctly states that the formal decision to activate the trauma team is not made in-field, but in-hospital by the ED nurse. We still used the term field triage, in an attempt to differentiate the study from those that describe traditional ED triage algorithms. Regardless of where the formal decision is made, triage decisions made before the patient arrives in the ED are based upon information gathered in-field and the triage decision have infield consequences.

We agree with Dr. Sandberg that it is difficult to isolate the aetiology of over- and undertriage. Over- and undertriage rates reflect a chain of events. We did not attempt to identify the link in this chain with most potential for improvement. This is reflected in our recommended improvement initiatives that address every major link in the trauma triage chain: improved on-scene patient evaluation, better routines in communicating patient data from EMS units to the nurse coordinator in the $\mathrm{ED}$, additional training in triage decision-making for nurse coordinators, and development of a two-tiered trauma triage protocol.

We acknowledge the complexity of describing undertriage in multi-centre trauma systems. Our analysis was limited to patients primary admitted to Ulleval University Hospital and did not include those admitted elsewhere in the trauma system. Although not studying the entire trauma system, the article's main findings support the general tendency of imprecise trauma triage in several Scandinavian studies [2-5]. This trend deserves verification through a 
Norwegian pan-trauma system analysis facilitated by the hopefully soon-to-be national trauma registry.

A degree of both over- and undertriage is unavoidable, and trauma systems should prepare for handling undertriage most effectively. One possible contribution to effectively identify patients subject to undertriage would be to introduce protocol-based ED triage algorithms as a safety net. By introducing a minor trauma team that systematically evaluates patients with uncertain injury panorama, the hospital acknowledges the difficulty of evaluating patients in-field by lowering the threshold for trauma team activation. This two-tiered system may contribute to lowering the undertriage rate while reducing the impact of overtriage. In our opinion a constructive combination.

\section{References}

I. Rehn M, Eken T, Kruger AJ, Steen PA, Skaga NO, Lossius HM: Precision of field triage in patients brought to a trauma centre after introducing trauma team activation guidelines. Scand J Trauma Resusc Emerg Med 2009, 17:I.

2. Lossius HM, Langhelle A, Pillgram-Larsen J, Lossius TA, Soreide E, Laake P, Steen PA: Efficiency of activation of the trauma team in a Norwegian trauma referral centre. European Journal of Surgery 2000, 166:760-764.

3. Kruger A], Hesselberg N, Abrahamsen GT, Bartnes K: [When should the trauma team be activated?]. Tidsskrift for Den Norske Laegeforening 2006, I 26:1335-1337.

4. Uleberg O, Vinjevoll OP, Eriksson U, Aadahl P, Skogvoll E: Overtriage in trauma - what are the causes? Acta Anaesthesiologica Scandinavica 2007, 5 I: I I78-II83.

5. Kann SH, Hougaard K, Christensen EF: Evaluation of pre-hospital trauma triage criteria: a prospective study at a Danish level I trauma centre. Acta Anaesthesiologica Scandinavica 2007, 5 I: II72-II77.

Publish with Biomed Central and every scientist can read your work free of charge

"BioMed Central will be the most significant development for disseminating the results of biomedical research in our lifetime. "

Sir Paul Nurse, Cancer Research UK

Your research papers will be:

- available free of charge to the entire biomedical community

- peer reviewed and published immediately upon acceptance

- cited in PubMed and archived on PubMed Central

- yours - you keep the copyright

Submit your manuscript here:

http://www.biomedcentral.com/info/publishing_adv.asp 